\title{
Methods for evaluation of helium/oxygen delivery through non-rebreather facemasks
}

Andrew R Martin ${ }^{1 *}$, Ira M Katz ${ }^{2,3}$, Yonatan Lipsitz ${ }^{2}$, Karine Terzibachi ${ }^{2}$, Georges Caillibotte ${ }^{2}$ and Joëlle Texereau ${ }^{2}$

\begin{abstract}
Background: Inhalation of low-density helium/oxygen mixtures has been used both to lower the airway resistance and work of breathing of patients with obstructive lung disease and to transport pharmaceutical aerosols to obstructed lung regions. However, recent clinical investigations have highlighted the potential for entrainment of room air to dilute helium/oxygen mixtures delivered through non-rebreather facemasks, thereby increasing the density of the inhaled gas mixture and limiting intended therapeutic effects. This article describes the development of benchtop methods using face models for evaluating delivery of helium/oxygen mixtures through facemasks.

Methods: Four face models were used: a flat plate, a glass head manikin, and two face manikins normally used in life support training. A mechanical test lung and ventilator were employed to simulate spontaneous breathing during delivery of 78/22 \%vol helium/oxygen through non-rebreather facemasks. Based on comparison of inhaled helium concentrations with available clinical data, one face model was selected for measurements made during delivery of $78 / 22$ or $65 / 35 \%$ vol helium/oxygen through three different masks as tidal volume varied between 500 and $750 \mathrm{ml}$, respiratory rate between 14 and 30 breaths/min, the inspiratory/expiratory ratio between 1/2 and 1/1, and the supply gas flow rate between 4 and $15 \mathrm{l} / \mathrm{min}$. Inhaled helium concentrations were measured both with a thermal conductivity analyzer and using a novel flow resistance method.

Results: Face models borrowed from life support training provided reasonably good agreement with available clinical data. After normalizing for the concentration of helium in the supply gas, no difference was noted in the extent of room air entrainment when delivering $78 / 22$ versus $65 / 35 \%$ vol helium/oxygen. For a given mask fitted to the face in a reproducible manner, delivered helium concentrations were primarily determined by the ratio of supply gas flow rate to simulated patient minute ventilation, with the inspiratory/expiratory ratio playing a secondary role. However, the functional dependence of helium concentration on these two ratios depended on the mask design.

Conclusions: Large differences in mask performance were identified. With continued refinement, the availability of reliable benchtop methods is expected to assist in the development and selection of patient interfaces for delivery of helium/oxygen and other medical gases.
\end{abstract}

Keywords: Facemask, Patient Interface, Helium, Oxygen, Heliox, Bench testing, Test lung, Face model, Head model, Manikin

\footnotetext{
* Correspondence: andrew.martin@airliquide.com

'Delaware Research and Technology Center, American Air Liquide, Newark, DE 19702, USA

Full list of author information is available at the end of the article
} 


\section{Background}

Inhalation of helium/oxygen $\left(\mathrm{He} / \mathrm{O}_{2}\right)$ mixtures has been explored as a means to lower the airway resistance and work of breathing of patients suffering from obstructive lung disease [1-6], and as a carrier gas to transport pharmaceutical aerosols to obstructed lung regions [7-12]. These effects stem from the physical properties of $\mathrm{He} / \mathrm{O}_{2}$ mixtures, in particular their low density compared to air [13-16]. As supplied, the He concentration in therapeutic $\mathrm{He} / \mathrm{O}_{2}$ mixtures typically ranges from $60 \%$ to $80 \%$, so as to balance between the low density afforded by high He concentration and the patient's supplemental $\mathrm{O}_{2}$ requirements. During noninvasive ventilation (NIV) combining $\mathrm{He} / \mathrm{O}_{2}$ with pressure support $[1,2]$, the tight fit of the NIV mask and the elevated pressure in the mask dead space combine to prevent entrainment of ambient room air and ensure that the targeted He concentration is inhaled by the patient. However, during unassisted spontaneous breathing, recent clinical investigations have highlighted the potential for room air entrainment to dilute $\mathrm{He} / \mathrm{O}_{2}$ mixtures delivered through standard non-rebreather facemasks $[17,18]$, thereby potentially limiting efficacy of $\mathrm{He} / \mathrm{O}_{2}$ therapy and certainly confounding efforts to determine optimal $\mathrm{He} / \mathrm{O}_{2}$ mixture concentrations when using non-rebreather masks.

The development of $\mathrm{He} / \mathrm{O}_{2}$ delivery strategies aimed at reducing room air entrainment (preferably while conserving gas consumption) will potentially entail design of purpose-made facemasks or other patient interfaces, improved means of matching supplied gas flows to patient demand, and/or use of semi-closed breathing circuits. Moreover, novel patient interfaces and gas supply means will be required for other medical gases, for example as new applications for nitric oxide, or for subanesthetic delivery of nitrous oxide and xenon, reach clinical evaluation. In the early-stages of product development, the availability of bench apparatus for collection of test data is advantageous, provided those test data can be trusted to be representative of use in the clinical setting. Evaluating facemask designs on the bench is particularly challenging given patient variation in facial features and size, and tolerance of fit tightness. While face models have been examined for testing aerosol drug delivery through facemasks $[19,20]$, little information is available on the suitability of face models for testing medical gas delivery interfaces.

The aim of the present study was to compare several approaches to evaluating $\mathrm{He} / \mathrm{O}_{2}$ delivery through nonrebreather facemasks on the bench. Four different face models were initially studied, ranging from a flat plate to more anatomically realistic manikins borrowed from life support training. Data obtained on the bench were compared with those obtained by Roche-Campo et al. [17] in a set of six healthy volunteers. Subsequently, a single face model was selected for a wider investigation of three different mask designs over a range of supply gas flow rates and simulated patient breathing patterns.

\section{Methods}

\section{Facemasks}

Three non-rebreather facemasks were studied, as pictured in Figure 1. These included a Pulmanex Hi-Ox mask (Viasys Healthcare, Netherlands), a Heliox21 mask (Intersurgical, UK), and a standard, three-valve reservoir mask (Intersurgical, UK). While the standard and $\mathrm{Hi}-\mathrm{Ox}$ masks were developed to deliver high oxygen concentrations, they have also been used for $\mathrm{He} / \mathrm{O}_{2}$ administration.

\section{Bench apparatus}

The experimental apparatus is shown schematically in Figure 2. Patient breathing was simulated using a dual chamber adult test lung (Michigan Instruments, USA) with the two chambers connected via a lifting bar. One chamber, the driving chamber, was connected to a ventilator (Neftis ICU; Taema, France) operated in volume control mode to impose breathing patterns, which varied in tidal volume between 500 and $750 \mathrm{ml}$, in respiratory rate between 14 and 30 breaths $/ \mathrm{min}$, and in the ratio of inspiratory time to expiratory time $\left(t_{i} / t_{e}\right)$ between $1 / 2$ and 1/1. All experiments were made with a constant (approximately square waveform) inspiratory flow. The second chamber, the breathing chamber, was connected to the various face models. Facemasks were fit to the face models, and $\mathrm{He} / \mathrm{O}_{2}$ (Air Liquide, France) was supplied to the facemasks at either $78 / 22$ or $65 / 35 \%$ vol through a gas blender (Sentry $\mathrm{He} / \mathrm{O}_{2}$ Blender; Cardinal Health, USA) at flow rates ranging from 4 to $15 \mathrm{l} / \mathrm{min}$.

\section{Face models}

Four different face models were evaluated. A sealed model was constructed simply by fixing the facemasks to a flat face plate using adhesive putty to create a gas-tight seal between the mask cuff and the plate. A $22 \mathrm{~mm}$ hole was cut in the face plate to fit an inlet for the throat described below. Again, this inlet was sealed to the face plate using adhesive putty. An open model employed a hollow glass manikin head with a $40 \mathrm{~mm}$ diameter hole cut out at the position of the mouth. For both the open and sealed models, a 'throat' was constructed from standard $15 \mathrm{~mm}$ medical tubing, a $90^{\circ}$ elbow connector, and an additional $15 \mathrm{~mm} \mathrm{ID/22} \mathrm{mm}$ OD adapter used to extend the throat to create an inlet at the position of the mouth. The dead volume between the throat inlet and the position from which gas was sampled for analysis was $100 \mathrm{ml}$. For the open model, Parafilm (Fisher Scientific, France) was used to close-off the mouth opening of the glass manikin around the throat inlet. 

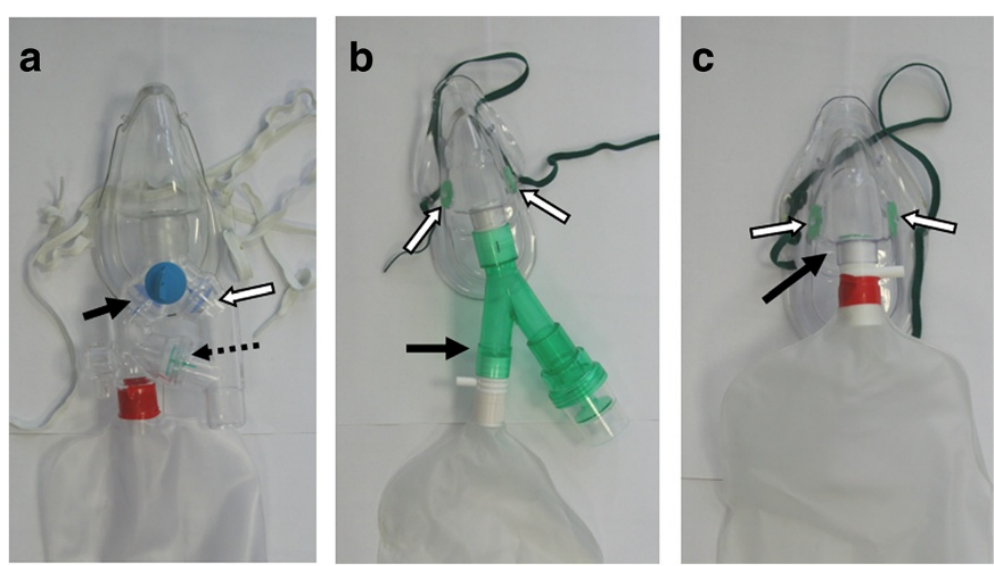

Figure 1 Non-rebreather facemasks evaluated in the present study: a) The Hi-Ox mask, b) the Heliox21 mask, and c) the standard mask. Black arrows indicate the positions of inhalation valves, while white arrows indicate the position of exhalation valves. The dotted arrow in a) indicates the position of the anti-suffocation valve.

Two face models used in life support training were also studied. For the Laerdal model, an adult manikin face (310210; Laerdal, Norway) was fitted over top of the glass manikin head as shown in Figure 3. The throat was kept in place, and the mouth opening of the manikin face was closed around the throat inlet, again using Parafilm, so as to simulate mouth breathing only. The Simulaids model employed a manikin face with upper airway (BLS Airway Trainer; Simulaids, UK), also shown in Figure 3. The nostrils of the model were plugged, and the outlet of the larynx was connected directly to tubing supplying the breathing chamber of the test lung, with the throat described above removed. The model had a second outlet, representing the esophagus, which was also plugged for all experiments. The total dead volume of the model was $230 \mathrm{ml}$.

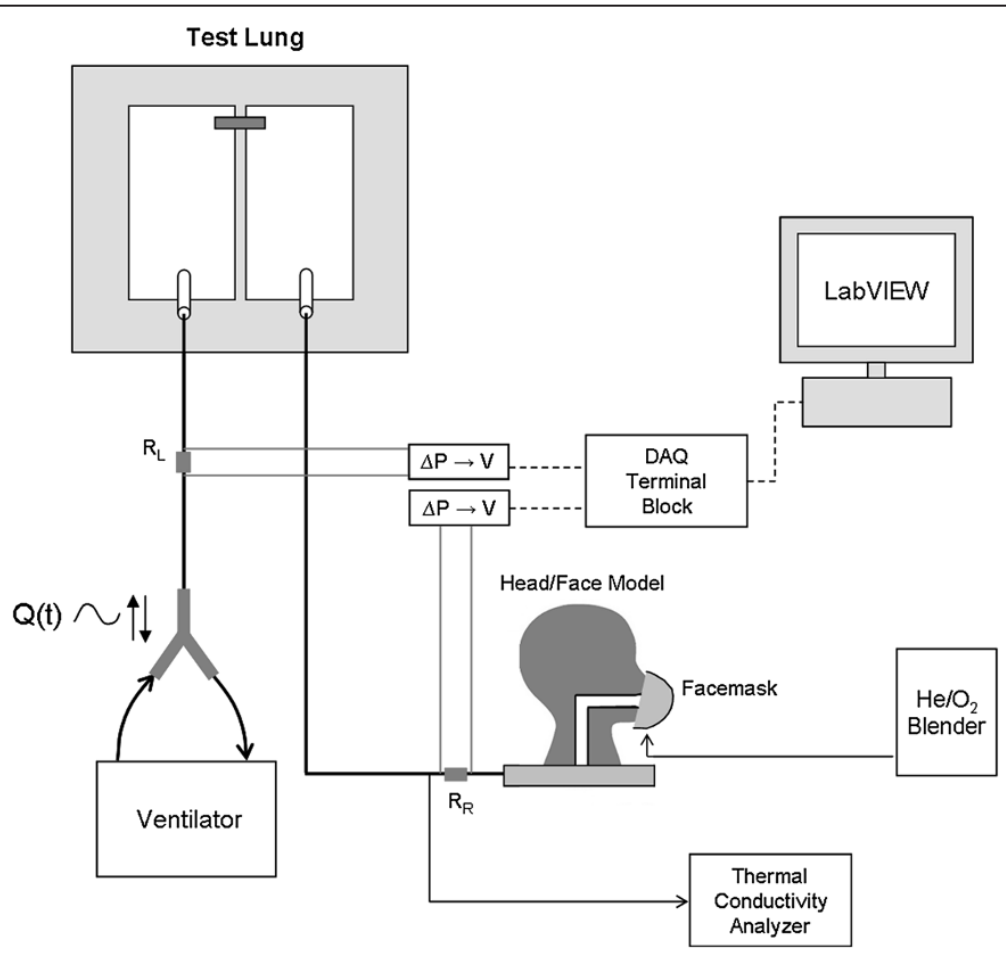

Figure 2 Schematic of the experimental apparatus used to test helium/oxygen $\left(\mathrm{He}_{\mathrm{O}} / \mathrm{O}_{2}\right)$ delivery through facemasks. $R_{R}$ and $R_{L}$ represent parabolic resistors $\left(R_{p} 5\right)$ placed in the flow paths supplying the right and left compartments of the test lung. $\Delta P \rightarrow V$ represents transducers used to convert the differential pressure measured across either resistor to a voltage signal sent to the data acquisition (DAQ) system. 


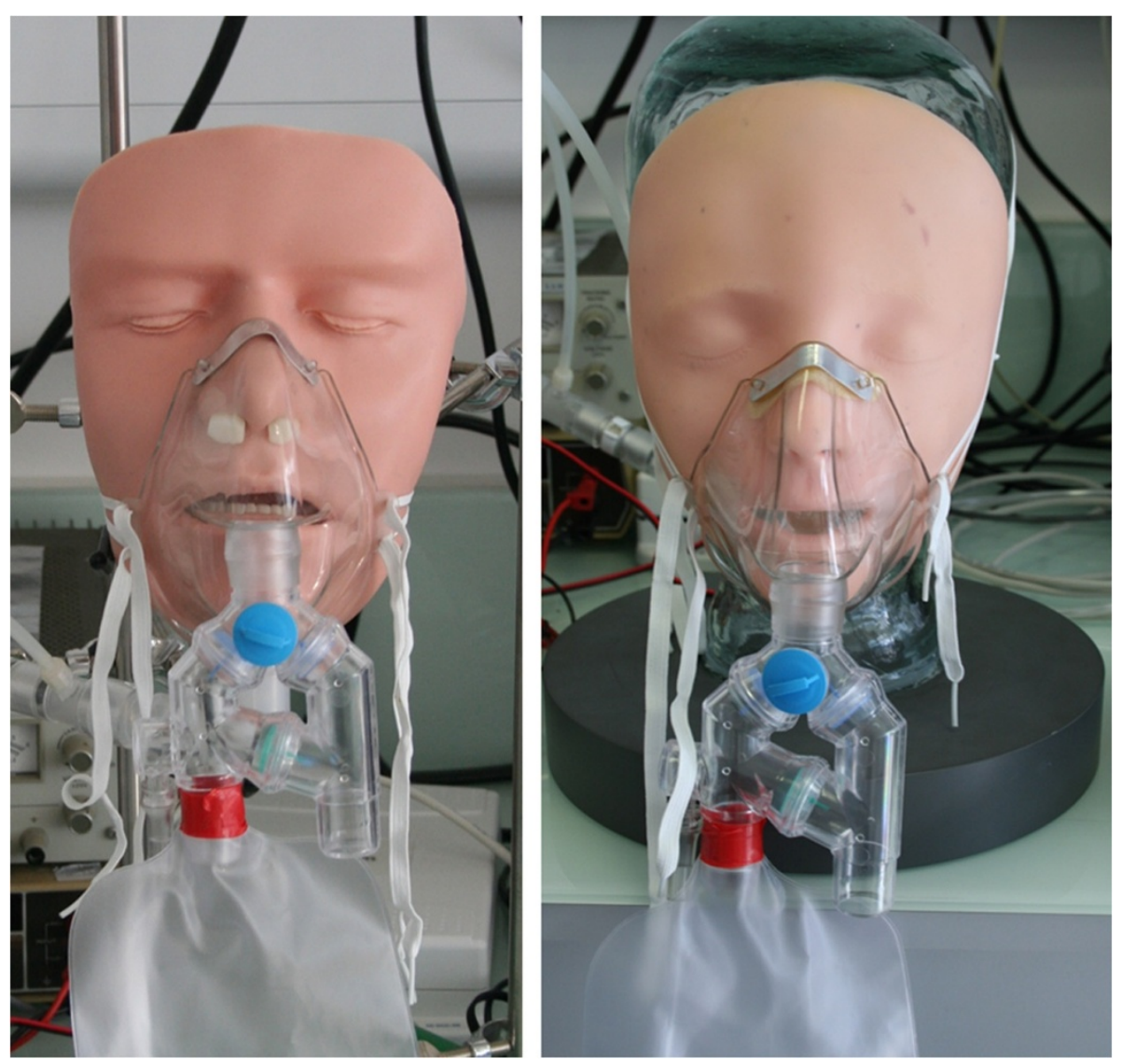

Figure 3 The Simulaids (left) and Laerdal (right) face models are shown fitted with the Hi-Ox mask.

\section{Helium concentration measurement}

Two methods were used to measure delivered helium concentrations. A thermal conductivity analyzer (KG6050; Hitech Instruments, UK), calibrated to measure the helium concentration in binary helium-oxygen mixtures, drew a continuous sample of $200-300 \mathrm{ml} / \mathrm{s}$ from tubing supplying the breathing chamber of the test lung. As specified by the manufacturer, the T90 response time of this analyzer is 20 seconds; accordingly, for each experiment, the measured helium concentration was allowed to reach steady state over several breaths before being recorded.

In addition, a flow resistance technique was used to obtain intra-breath measures of the helium concentration. Parabolic resistors (Rp5, PneuFlow; Michigan Instruments, USA) were inserted into the flow paths supplying the two breathing chambers of the test lung. The differential pressure across each of these resistors was monitored and recorded using pressure transducers (PX277-05D5V; Omega Engineering Inc, USA) and LabVIEW data acquisition software (National Instruments, USA). The pressure drop across these resistors depends on both the gas flow rate and density [13]; accordingly, on the driving side of the test lung, where the gas density was known to be that of air, the resistor served as a differential pressure flow sensor. This flow measurement, along with the pressure drop measured across the resistor positioned on the breathing side, allowed the density (and in turn the helium concentration) of the gas on the breathing side to be determined, based on calibration data previously obtained by supplying gas to the resistor at known flow rates and helium concentrations. For all experiments, both the thermal conductivity analyzer and the flow resistor method were used to measure delivered helium concentrations.

When using the Laerdal and Simulaids face models, it was found in preliminary experiments that small adjustments made when fitting masks to the faces produced large changes in measured helium concentrations. Furthermore, the quality of the fit was difficult to assess visually. As a consequence, masks were fit to these face models while supplying $\mathrm{He} / \mathrm{O}_{2}$ at $15 \mathrm{l} / \mathrm{min}$ and adjusting the fit to produce the highest possible helium concentration, as monitored using the thermal conductivity analyzer. The mask was then left in place and not adjusted while a series of measurements were performed at varying supply flow rate or breathing pattern. 


\section{Results and discussion}

\section{Comparison to clinical data}

Experiments were first performed with all four face models using the Hi-Ox mask supplied with 78/22 $\mathrm{He} /$ $\mathrm{O}_{2}$. These were made at a tidal volume of $500 \mathrm{ml}$ and respiratory rate of 30 breaths/min to match the average breathing parameters recorded during the in vivo measurements performed on healthy adults using the same mask at resting conditions by Roche-Campo et al. [17]. The ratio $t_{i} / t_{e}$ was fixed at $1 / 2$. Figure 4 compares the average inhaled helium concentrations measured with the thermal conductivity analyzer for the four face models with the mean and range of values measured in vivo. Concerning the face models, the sealed and open models represent upper and lower extremes in delivered helium concentrations, with values obtained for the Laerdal and Simulaids models falling in between. Little difference was observed between the average helium concentrations measured for the Laerdal and Simulaids face models, and concentrations measured using either of these models were in reasonable agreement with mean values measured in vivo in healthy adults. The series of experiments was repeated for the Heliox 21 and standard facemasks using only the Laerdal and Simulaids models, and results are presented in Table 1. Again, agreement with mean values measured in vivo was good, though when testing the Heliox 21 mask on the Simulaids model, helium concentrations delivered on the bench tended to lie just below the lower range of the in vivo dataset for the same mask.
Table 1 Average inhaled helium concentrations measured on the bench and in healthy adult subjects [17]

\begin{tabular}{|c|c|c|c|c|}
\hline \multicolumn{5}{|c|}{ Average inhaled He concentration } \\
\hline Mask & $\begin{array}{c}\text { Supply flow } \\
{[1 / \mathrm{min}]}\end{array}$ & $\begin{array}{c}\text { Laerdal } \\
{[ \pm 2 \%]}\end{array}$ & $\begin{array}{c}\text { Simulaids } \\
\text { [ } \pm 2 \%]\end{array}$ & $\begin{array}{c}\text { Clinical data } \\
\text { [mean (range)\%] }\end{array}$ \\
\hline \multirow[t]{4}{*}{$\mathrm{Hi}-\mathrm{Ox}$} & 15 & 52.2 & 54.3 & $60.1(52.3-67.8)$ \\
\hline & 12 & 49.4 & 52.4 & $53.5(42.5-66.0)$ \\
\hline & 10 & 47.1 & 46.2 & $45.0(30.5-59.9)$ \\
\hline & 7 & 43.1 & 37.4 & $41.5(26.3-52.8)$ \\
\hline \multirow[t]{4}{*}{ Heliox21 } & 15 & 37.9 & 32.9 & $54.9(35.4-69.9)$ \\
\hline & 12 & 34.1 & 28.9 & $46.1(30.7-57.7)$ \\
\hline & 10 & 31.7 & 25.3 & $38.3(31.1-47.0)$ \\
\hline & 7 & 27.2 & 20.6 & $28.2(18.8-35.3)$ \\
\hline \multirow[t]{4}{*}{ Standard } & 15 & 36.5 & 42.1 & $50.9(41.4-63.1)$ \\
\hline & 12 & 32.7 & 36.3 & $42.2(30.5-54.6)$ \\
\hline & 10 & 29.6 & 31.6 & $36.7(26.3-43.3)$ \\
\hline & 7 & 24.9 & 26.1 & $26.7(20.9-32.3)$ \\
\hline
\end{tabular}

\section{Helium concentration measurement}

The response time of the thermal conductivity analyzer was sufficiently slow that measured values represent time-averaged helium concentrations over several breaths. In contrast, using the flow resistor method it was possible to resolve variation in inhaled helium concentration within a single breath. Example data is shown in Figure 5, which was taken for the $\mathrm{Hi}-\mathrm{Ox}$ mask supplied with $10 \mathrm{l} / \mathrm{min}$ of $78 / 22 \% \mathrm{He} / \mathrm{O}_{2}$ and fit to each of the four face models. All data shown in Figure 5 were obtained at a tidal volume of $500 \mathrm{ml}$, a respiratory rate

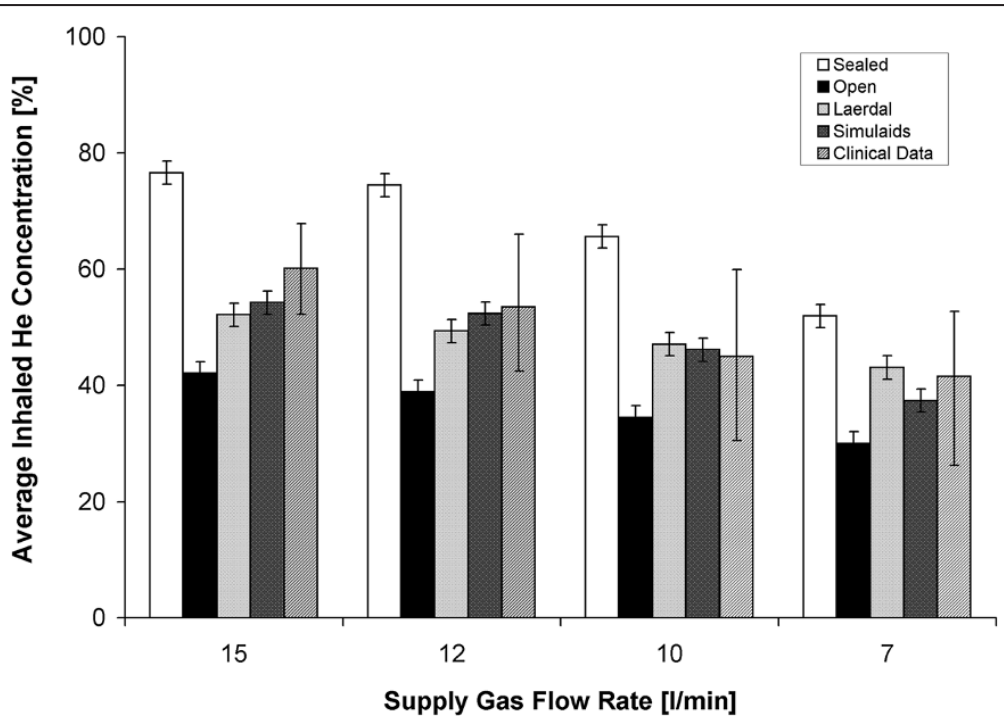

Figure 4 Average inhaled helium concentrations for the Hi-Ox mask are displayed for a range of supply flow rates of helium/oxygen $\left(\mathrm{He} / \mathrm{O}_{2}\right) \mathbf{7 8 / 2 2}$. For the clinical data [17], error bars represent the limits of the range of values measured for six healthy, adult subjects. For all other columns, data was obtained from bench measurements made using the thermal conductivity analyzer. Error bars represent the $\pm 2 \%$ accuracy of the analyzer. 


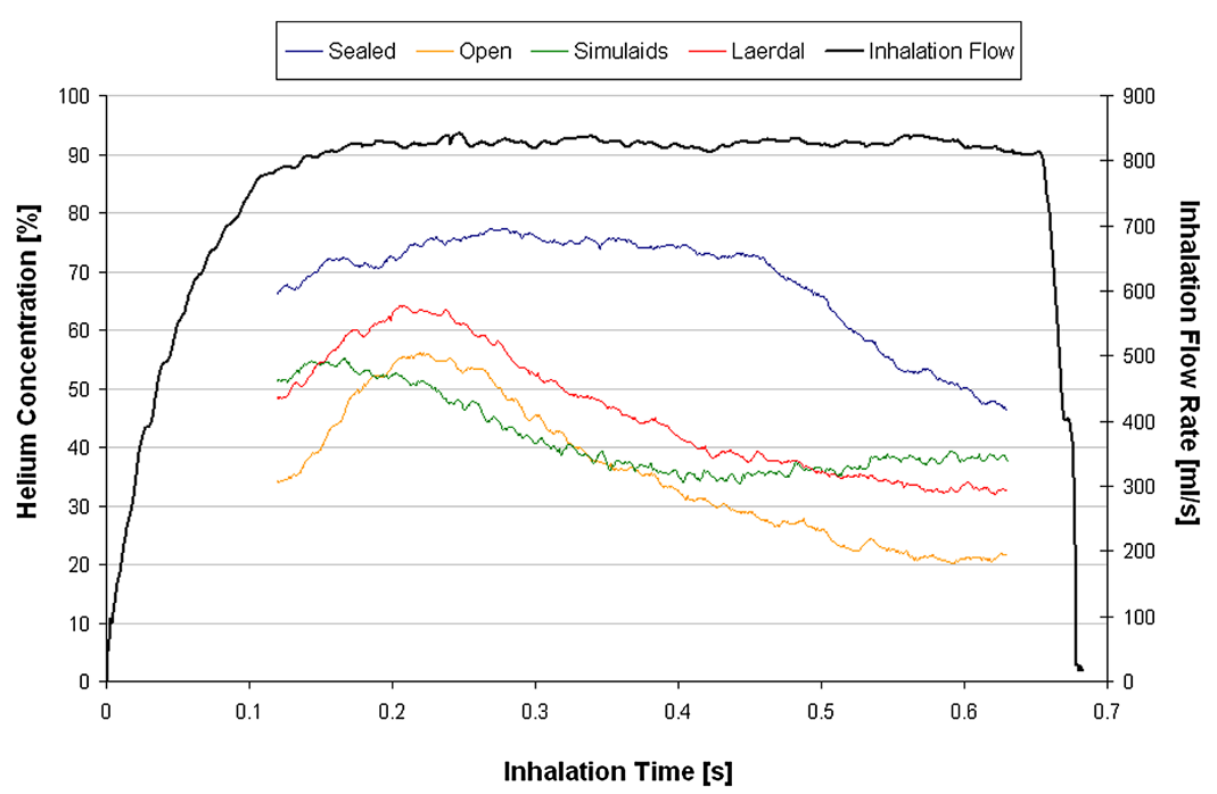

Figure 5 An example of data obtained using the flow resistance method for determining inhaled helium concentrations, taken for the $\mathrm{Hi}$-Ox mask supplied with $10 \mathrm{l} / \mathrm{min}$ of $78 / 22 \%$ helium/oxygen $\left(\mathrm{He} / \mathrm{O}_{2}\right)$, while ventilating at $30 \mathrm{breaths} / \mathrm{min}$ with a tidal volume of $\mathbf{5 0 0 ~ m l}$ and a ratio $\mathbf{t}_{\mathbf{i}} / \mathbf{t}_{\mathrm{e}}$ of $\mathbf{1 / 2}$. Each curve is an average of data obtained over seven consecutive breaths. Also shown is a representative trace showing the inspiratory flow pattern.

of $30 \mathrm{breaths} / \mathrm{min}$, and a ratio $\mathrm{t}_{\mathrm{i}} / \mathrm{t}_{\mathrm{e}}$ of $1 / 2$. Also shown in Figure 5 is a representative trace showing the inspiratory flow pattern. Note that helium concentration data are not reported in Figure 5 at the start and end of the breath. This is a limitation of the measurement approach; during periods of rapid flow rate increase or decrease, instantaneous flow rates in the driving and breathing sides of the test lung are not equal, with the breathing chamber generally lagging the driving chamber. As a result, the flow rate derived from the pressure drop measured across the resistor on the driving side is different from the flow rate on the breathing side, and will lead to errors if used in the derivation of the helium concentration as described above.

Nevertheless, several useful pieces of information are conveyed in Figure 5. First, even for the sealed model, the delivered helium concentration falls off towards the end of the breath. This should not be surprising considering the ratio of gas supply flow relative to the simulated patient demand. At a tidal volume $500 \mathrm{ml}$ and respiratory rate of 30 breaths $/ \mathrm{min}$, the inhaled minute volume is $15 \mathrm{l} / \mathrm{min}$. Accordingly, supplying $10 \mathrm{l} / \mathrm{min}$ to a non-rebreather mask requires that an additional $5 \mathrm{l} / \mathrm{min}$ of gas be entrained from the room every minute. With the mask tightly sealed to the faceplate, this can be considered a controlled room air dilution, in that dilution occurs through an anti-suffocation valve, positioned on the mask's supply manifold, and towards the end of the breath, once the reservoir bag is emptied. For the other three face models studied, where leaks occurred between the mask cuff and the face, there was an additional uncontrolled dilution, for which the location and timing during the breath are not obvious. In these cases, the inhaled helium concentration never reached the $78 \%$ contained in the supply flow.

Still with reference to Figure 5, all four curves initially rise near the beginning of the breath before later falling. We hypothesize that the former effect occurred due to inhalation of gas from the combined dead volumes of the models and masks. The helium concentration in the dead volume would be that of gas expired from the breathing chamber, and as such would be lower than that of the source gas. Therefore, it is likely that inhaled helium concentrations initially rose as fresh gas from the source flow and reservoir bag washed into the dead volume, before peaking and then falling off as the reservoir emptied. Such an effect could also explain the different pattern seen for the Simulaids model as compared to the Laerdal and open models, with the flatter curve for the Simulaids model linked to its larger dead volume.

Figure 6 compares helium concentrations measured using the flow resistor method and averaged over an inhalation with those measured by the thermal conductivity analyzer. As seen the two methods were in close agreement, which can be viewed as a validation of the flow resistor method, but also as evidence that the steady-state reading on the thermal conductivity analyzer did indeed represent a time-averaged helium concentration. Given its ease of use and commercial availability, the thermal conductivity analyzer seems a 


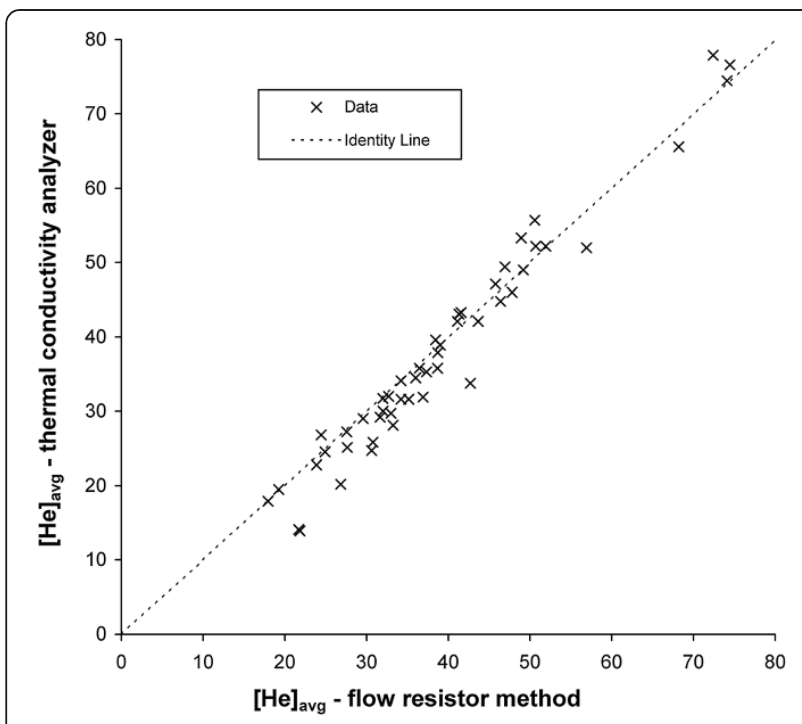

Figure 6 The time-averaged inhaled helium concentration, $[\mathrm{He}]_{\text {avg, }}$ measured using the flow resistance method is plotted against that measured by the thermal conductivity analyzer.

reasonable candidate for implementation of similar testing procedures across laboratories.

\section{Parameter study}

In an effort to further investigate the performance of the three masks, additional experiments were conducted over the full parameter range described in the Methods section, using only the Simulaids model. This model was chosen primarily because it was used as supplied by the manufacturer without modification, and as such would lend itself most easily to use in other laboratories. Figure 7 displays data from the full range of the experiments. Delivered helium concentrations are plotted against the ratio of supply flow rate to minute volume $\left(\mathrm{Q}_{\mathrm{S}} / \mathrm{V}_{\mathrm{E}}\right)$. As experiments were conducted with both 78/ 22 and $65 / 35 \% \mathrm{He} / \mathrm{O}_{2}$, delivered helium concentrations were normalized by the supplied concentration. With this normalization, data obtained using either mixture appear to follow the same trend. That is to say, the relatively small differences in gas properties between $78 / 22$ and $65 / 35 \% \mathrm{He} / \mathrm{O}_{2}$ [16] did not influence room air entrainment, such that results obtained when testing with one $\mathrm{He} / \mathrm{O}_{2}$ mixture can be readily extrapolated to predict inhaled concentrations that would be delivered when supplying a different $\mathrm{He} / \mathrm{O}_{2}$ mixture, at least so long as the helium concentration in those mixtures ranges between 65 and $78 \%$.

Again with reference to Figure 7, two regions of the curves can be defined. First, when the ratio $\mathrm{Q}_{\mathrm{s}} / \mathrm{V}_{\mathrm{E}}$ is less than one (that is when minute ventilation exceeds the supply flow rate) the masks can be considered to be undersupplied. In this case, the Hi-Ox mask outperformed both the standard mask and the Heliox 21 mask. This is likely a result of the superior function of the expiratory valve on the Hi-Ox mask. As has been noted by previous investigators [21], expiratory flap-valves placed on standard masks permit room air entrainment during inhalation. By replacing these with a valve positioned in the gas supply manifold, which remains closed during inhalation, the design of the $\mathrm{Hi}-\mathrm{Ox}$ mask promotes

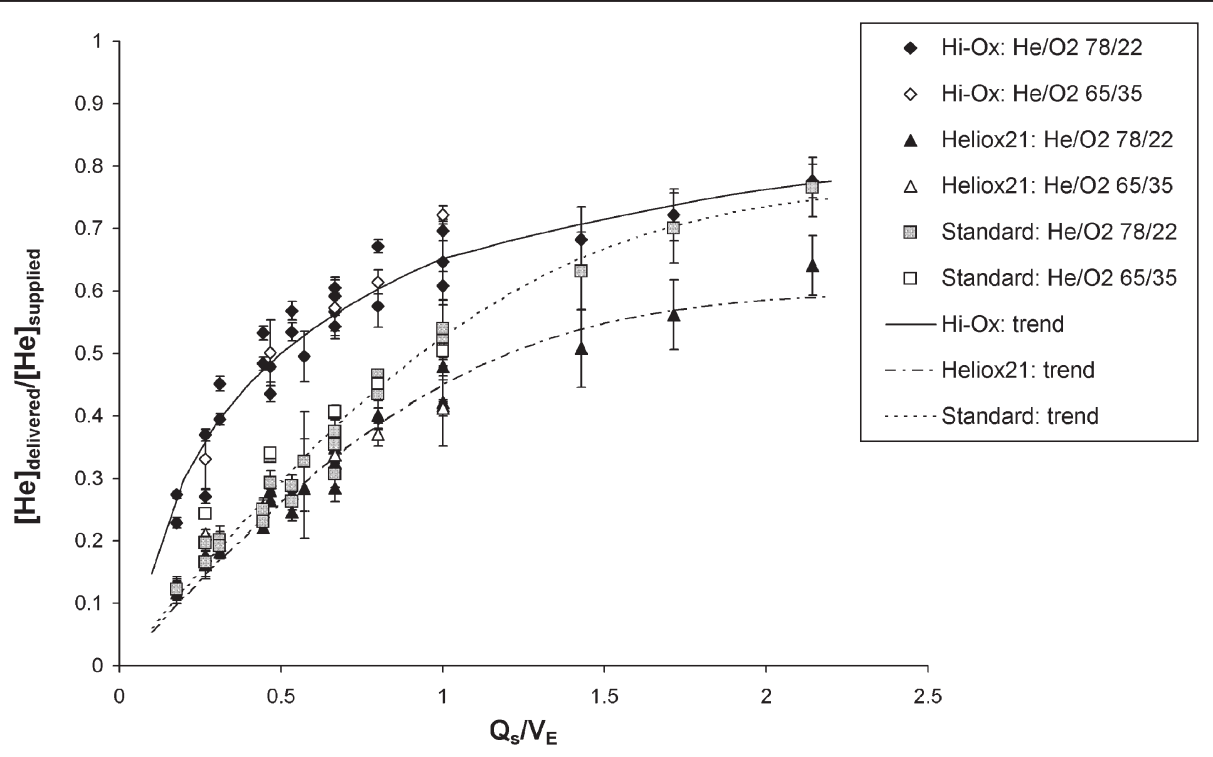

Figure 7 The normalized delivered helium concentration, $[\mathrm{He}]_{\text {delivered }} /[\mathrm{He}]_{\text {supplied, }}$ is plotted against the ratio between the supply gas flow rate and minute ventilation, $\mathrm{Q}_{5} / \mathrm{V}_{\mathrm{E}}$, for each of the three masks tested, supplied with $78 / 22$ or $65 / 35 \% \mathrm{vol}$ helium/oxygen (He/ $/ \mathrm{O}_{2}$ ). For comparison, trend lines are also shown for each mask. Error bars represent standard deviations around mean values $(n=3)$. 


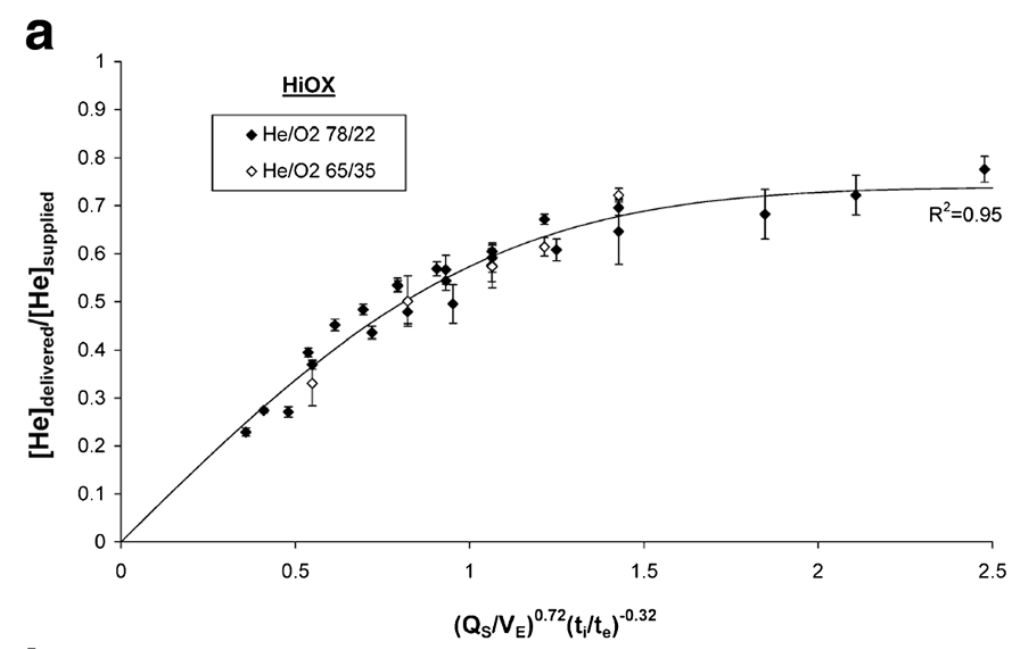

b
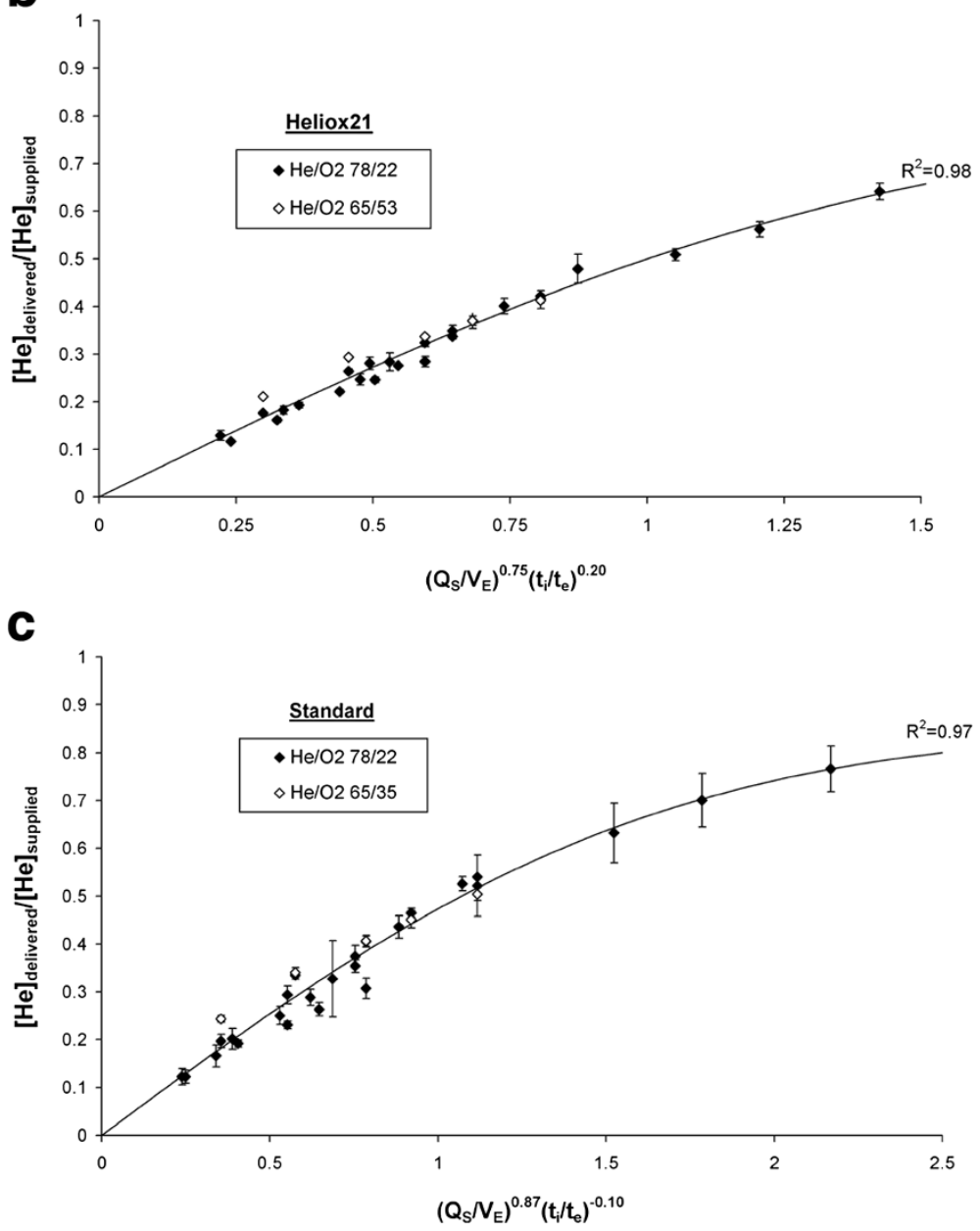

Figure 8 The normalized delivered helium concentration, $[\mathrm{He}]_{\text {delivered }} /[\mathrm{He}]_{\text {supplied, }}$ is plotted against a composite parameter that includes the ratio between the supply gas flow rate and minute ventilation, $\mathrm{Q}_{\mathrm{s}} / \mathrm{V}_{\mathrm{E}}$, and the ratio between inspiratory and expiratory times, $\mathbf{t}_{\mathrm{i}} / \mathrm{t}_{\mathrm{e}}$, for a) the Hi-Ox mask, b) the Heliox21 mask, and c) the standard mask. Error bars represent standard deviations around mean values $(n=3)$. For each mask, the exponents in the composite parameter were determined through a least-squares fit of Equation (1) to the experimental data. Best-fit curves, and associated $R^{2}$ values, are shown for each mask. 
emptying of the reservoir prior to a controlled room air entrainment [21]. This sequential function was clearly observable when conducting the experiments, whereas for the other two masks the reservoir bags did not completely empty, even when the masks were undersupplied.

When the ratio $Q_{s} / V_{E}$ exceeded one, such that the masks can be said to be oversupplied, inhaled helium concentrations delivered through the standard mask approached those delivered through the Hi-Ox mask, while concentrations delivered through the Heliox 21 mask remained lower. We hypothesize that as the gas supply becomes increasingly high relative to patient demand, the conserving function provided by the reservoir becomes less critical, and that instead it is the relative resistance of the supply flow path compared to that of uncontrolled leak paths that determines room air entrainment. On the Heliox 21 mask the inspiratory valve is positioned further from the patient compared to the standard mask, and the resulting small increase in resistance between the fresh gas supply and the patient may promote entrainment of air through leak paths.

Differences in mask performance are further investigated in Figure 8. Data obtained for each mask were fit with functions of the form:

$$
\frac{[H e]_{\text {delivered }}}{[H e]_{\text {supplied }}}=A * \operatorname{erf}\left[B *\left(\frac{Q_{s}}{V_{E}}\right)^{C}\left(\frac{t_{i}}{t_{e}}\right)^{D}\right]
$$

where the constants $A, B, C$, and $D$ were determined for each mask by least-squares fitting, and are provided in Table 2. The error function (erf) is defined in the Appendix, and was selected here based solely on goodness of fit to the data in comparison with several other functions of similar shape.

Examining equation (1), the ratio $\mathrm{Q}_{\mathrm{S}} / \mathrm{V}_{\mathrm{E}}$ provides a measure of the supply gas flow relative to patient demand as discussed above. The ratio between the inspiratory and expiratory times $\left(t_{i} / t_{e}\right)$ was included because with all else held constant, changes to this ratio affect inspiratory flow rates, which play a role in determining the relative resistances of supply and leak flow pathways. The absolute values of the constants $C$ and $D$, relative to one another, provide an indication of the relative sensitivity of delivered helium concentrations to these two terms. For all three masks, the ratio $\mathrm{Q}_{\mathrm{S}} / \mathrm{V}_{\mathrm{E}}$ was the

Table 2 Best-fit coefficients used in equation 1 for each facemask

\begin{tabular}{lcccc}
\hline \multicolumn{5}{c}{ Coefficient } \\
\hline Mask & A & B & C & D \\
\hline Hi-Ox & 0.7391 & 0.8601 & 0.7233 & -0.3210 \\
\hline Heliox21 & 0.8096 & 0.6169 & 0.7478 & 0.1950 \\
\hline Standard & 0.8454 & 0.5460 & 0.8694 & -0.1001 \\
\hline
\end{tabular}

dominant term. Of further interest, the coefficient $D$ was opposite in sign for the Heliox21 mask than for the other two masks. That is to say, for the $\mathrm{Hi}-\mathrm{Ox}$ and standard masks, increasing inspiratory times, associated with lower inspiratory flow rates, tended to increase delivered helium concentrations, whereas for the Heliox 21 mask the effect was opposite. This result may be related to the hypothesis provided above, in that for the Heliox 21 mask lower flow rates tended to favor flow through leaks over that from the fresh gas supply; however, no firm conclusions should be drawn without a more detailed analysis of the underlying fluid mechanics.

Finally, though the data shown in Figure 8 collapse tightly when plotted against the two ratios, $\mathrm{Q}_{\mathrm{s}} / \mathrm{V}_{\mathrm{E}}$ and $\mathrm{t}_{\mathrm{i}} /$ $t_{e}$, it is important to note that our methodology included a procedure to fit the masks to the face model in a reproducible manner. Clearly, variation in the quality and tightness of fit between the mask cuff and the face will affect delivered gas concentrations, and this variation is not captured in the experiments reported here.

\section{Suggestions for improved face models}

While the bench data reported herein were in reasonable agreement with available clinical data, a number of points could be improved in future test designs. First, even though masks were adjusted to produce as good a fit as possible, the delivered helium concentrations determined using the Laerdal and Simulaids models tended to fall near, or in some cases even below, the lower range of values measured in humans. Some discrepancy may be expected due to variation in individual subjects' breathing patterns around the average values that were reproduced on the bench; however, tactile examination of the face models suggests that they are both smoother and harder than a typical human face. Given that neither face model was specifically designed for the purpose of mask testing, it may be that a purpose-built model, for example one that simulates a layer of soft tissue over a hard bone-like structure, will allow clinical mask performance to be more accurately reproduced. Borrowing from evaluation of masks used for aerosol delivery, such a model could also allow delivered gas concentrations to be assessed as a function of the force with which the mask is applied to the face $[19,20,22]$, with an ideal mask maintaining high concentrations at low force. To enable such assessment, a purpose-built model should include the entire head (in contrast to the Simulaids face model selected for the present study) given that facemasks used for gas delivery include a variety of straps or harnesses that secure around the back of the head. Potential differences between oral and nasal breathing also merit investigation, especially for applications where variation in breathing route over time or between patients is expected. 


\section{Conclusions}

As new applications of medical gases reach the stage of clinical evaluation, the need for novel patient interfaces and gas supply means will increase. In the present work, two face manikins normally used in life support training were incorporated into a bench top model for assessing delivery of $\mathrm{He} / \mathrm{O}_{2}$ through facemasks, and shown to reproduce available clinical data with reasonable accuracy. Experiments were then conducted to explore variation in delivered helium concentrations between three nonrebreather facemasks, and large differences in mask performance were identified. With continued refinement, it is anticipated that the availability of reliable benchtop methods for evaluating facemask and other patient interface designs will help to accelerate the development process and assist in demonstrating clinical effectiveness of medical gases.

\section{Appendix}

The error function is a mathematical function of the form

$$
\operatorname{erf}(x)=\frac{2}{\sqrt{\pi}} \int_{0}^{x} e^{-t^{2}} d t
$$

which owes its name to its original use in measurement theory, but is now used more widely in various branches of mathematics and engineering.

The error function is included as a built-in function in most mathematical software packages, and is available in Microsoft EXCEL after installation of the Analysis ToolPak add-in.

\section{Competing interests}

At the time of the study, all authors were employed by Air Liquide, a company that produces helium/oxygen mixtures and is conducting clinical trials to assess their efficacy in the management and treatment of respiratory diseases.

\section{Authors' contributions}

AM conceived of the study, designed the experiments, participated in performing the bench experiments, and wrote the manuscript. IK participated in the conception and design of the study, and edited the manuscript. YL participated in the design of experiments, performed the majority of bench experiments, and contributed to drafting the manuscript. $K T$ participated in the design of experiments, and created the data acquisition system. GC participated in the design of the experiments. JT participated in the conception and design of the study, and edited the manuscript. All authors read and approved the final manuscript.

\section{Author details}

'Delaware Research and Technology Center, American Air Liquide, Newark, DE 19702, USA. ${ }^{2}$ Medical Gases Group, Air Liquide Santé International, Les Loges-en-Josas 78354, France. ${ }^{3}$ Department of Mechanical Engineering, Lafayette College, Easton, PA 18042, USA.

Received: 26 November 2012 Accepted: 12 December 2012

Published: 17 December 2012

\section{References}

1. Jolliet P, Tassaux D, Roeseler J, Burdet L, Broccard A, D'Hoore W, Borst F, Reynaert M, Schaller MD, Chevrolet JC: Helium-oxygen versus air-oxygen noninvasive pressure support in decompensated chronic obstructive disease: A prospective, multicenter study. Crit Care Med 2003, 31:878-884.

2. Maggiore SM, Richard JCM, Abroug F, Diehl JL, Antonelli M, Sauder P, Mancebo J, Ferrer M, Lellouche F, Lecourt L, Beduneau G, Brochard L: A multicenter, randomized trial of noninvasive ventilation with helium-oxygen mixture in exacerbations of chronic obstructive lung disease. Crit Care Med 2010, 38:145-151.

3. Hess DR: Heliox and noninvasive positive-pressure ventilation. A role for heliox in exacerbations of chronic obstructive pulmonary disease? Respir Care 2006, 51:640-650

4. Kass JE, Terregino CA: The effect of heliox in acute severe asthma - A randomized controlled trial. Chest 1999, 116:296-300.

5. Rodrigo GJ, Rodrigo C, Pollack CV, Rowe B: Use of helium-oxygen mixtures in the treatment of acute asthma - A systematic review. Chest 2003, 123:891-896.

6. Diehl J-L, Peigne V, Guérot E, Faisy $C$, Lecourt $L$, Mercat $A$ : Helium in the adult critical care setting. Annals Intens Care 2011, 1:24.

7. Kim IK, Saville AL, Sikes KL, Corcoran TE: Heliox-driven albuterol nebulization for asthma exacerbations: An overview. Respir Care 2006, 51:613-618.

8. Anderson M, Svartegren M: Deposition in asthmatics of $3.5 \mu \mathrm{m}$ particles suspended in air and in helium-oxygen mixture. Am Rev Respir Dis 1993, 147:524-528.

9. Peterson JB, Prisk GK, Darquenne C: Aerosol deposition in the human lung periphery is increased by reduced-density gas breathing. J Aerosol Med Pulm Drug Del 2008, 21:159-168.

10. Corcoran TE, Gamard S: Development of aerosol drug delivery with helium oxygen gas mixtures. J Aerosol Med 2004, 17:299-309.

11. Kress JP, Noth I, Gehlbach BK, Barman N, Pohlman AS, Miller A, Morgan S, Hall JB: The utility of albuterol nebulized with heliox during acute asthma exacerbations. Am J Respir Crit Care Med 2002, 165:1317-1321.

12. Martin AR, Ang A, Katz IM, Haussermann S, Caillibotte G, Texereau J: An in vitro assessment of aerosol delivery through patient breathing circuits used with medical air or a helium-oxygen mixture. J Aerosol Med Pulm Drug Del 2011, 24:225-234.

13. Katz IM, Martin AR, Muller P-A, Terzibachi K, Feng C-H, Caillibotte G, Sandeau J, Texereau J: The ventilation distribution of helium-oxygen mixtures and the role of inertial losses in the presence of heterogeneous airway obstructions. J Biomechanics 2011, 44:1137-1143.

14. Brighenti C, Barbini P, Gnudi G, Cevenini G, Pecchiari M, D'Angelo E: Helium-oxygen ventilation in the presence of expiratory flowlimitation: A model study. Respir Physiol Neurobiol 2007, 157:326-334.

15. Papamoschou D: Theoretical validation of the respiratory benefits of helium-oxygen mixtures. Respir Physiol 1995, 99:183-190.

16. Katz IM, Caillibotte G, Martin AR, Arpentinier P: Property value estimation for inhaled therapeutic binary gas mixtures: $\mathrm{He}, \mathrm{Xe}$, $\mathrm{N}_{2} \mathrm{O}$, and $\mathrm{N}_{2}$ with $\mathrm{O}_{2}$. Med Gas Res 2011, 1:28.

17. Roche-Campo F, Vignaux L, Galia F, Lyazidi A, Vargas F, Texereau J, Apiou-Sbirlea G, Jolliet P, Brochard L: Delivery of helium-oxygen mixture during spontaneous breathing: evaluation of three highconcentration face masks. Intensive Care Med 2011, 37:1787-1792.

18. Standley TDA, Smith HL, Brennan LJ, Wilkins IA, Bradley PG, Barrera Groba C, Davey AJ, Menon DK, Wheeler DW: Room air dilution of heliox given by facemask. Intensive Care Med 2008, 34:1469-1476.

19. Mitchell JP, Finlay B, Nuttall JM, Limbrick MR, Nagel MW, Avvakoumova VI, MacKay HA, Ali RS, Doyle CC: Validation of a new model infant face with nasopharynx for testing of valved holding chambers (VHCs) with facemask as a patient interface. In Respiratory drug delivery 2010. Edited by Dalby RN, Byron PR, Peart J, Suman JD, Farr SJ, Young PM. USA: Virginia Commonwealth University; 2010:777-780.

20. Hsu W, Bai T, von Hollen D, Nikander K, Dalby R: Realistic evaluation of a valved holding chamber with facemask - using a soft anatomical model face to evaluate aerosol output under simulated use conditions. In Respiratory drug delivery 2010. Edited by Dalby RN, 
Byron PR, Peart J, Suman JD, Farr SJ, Young PM. USA: Virginia Commonwealth University; 2010:835-838.

21. Slessarev M, Somogyi R, Preiss D, Vesely A, Sasano H, Fisher JA: Efficiency of oxygen administration: Sequential gas delivery versus "flow in a cone" methods. Crit Care Med 2006, 34:829-834.

22. Finlay WH, Martin AR: Modeling of aerosol deposition with interface devices. J. Aerosol Med 2007, 20:S19-S28.

doi:10.1186/2045-9912-2-31

Cite this article as: Martin et al:: Methods for evaluation of helium/

oxygen delivery through non-rebreather facemasks. Medical Gas Research 2012 2:31

\section{Submit your next manuscript to BioMed Central and take full advantage of:}

- Convenient online submission

- Thorough peer review

- No space constraints or color figure charges

- Immediate publication on acceptance

- Inclusion in PubMed, CAS, Scopus and Google Scholar

- Research which is freely available for redistribution 